\title{
Analysis for Subjective Well-being of Xi'an Preschool Teachers
}

\author{
Cai Jun \\ Infant Normal College \\ Xi'an University of Arts and Science \\ Xi'an, China \\ e-mail: xacaijun@126.com
}

\begin{abstract}
The research used the Subjective Well-being Scale for Chinese Citizen (SWBS-CC) to measure the 102 preschool teachers' SWB in Xi'an of China. The results showed that the surveyed teachers' SWB is not optimistic overall. Firstly, the higher the age, the lower the SWB. Secondly, the longer of service, the lower the SWB. Thirdly, SWB of preschool teachers with different income are not significant different. Finally, the main factors which can affect SWB of preschool teachers are children, parents, infant school, teachers' career identification, social recognition, and etc.
\end{abstract}

Keywords-preschool teacher, subjective well-being, influencing factors

\section{INTRODUCTION}

Well-being is an emotion condition produced when individual realized he had satisfied himself and had achieved his ideal. And also it is a complex and multilevel psychological condition which is interactively formed by mental factors that means and external causes. Mental factor means demand (includes intention, desire, interests), cognition, emotion and etc. Education is a happy career and preschool teachers is also a happy career[1]. Subjective Well-being (shorted as SWB) is a important comprehensive psychological index to value the living quality of human being.[2] Some research shows that individual with higher SWB works more effectively and has more social adaptability (Michael Aigyle, 2001). So the level of teachers' SWB not only effect their working enthusiasm, but also affect their teaching keenness degree and even their career stability.

\section{PROPOSAL OF THE PROBLEMS}

\section{A. Background}

Teacher is the basic of education program. The integral level of preschool teacher team can directly affect the mind and body growth of children and quality of children education. Some preschool teachers enjoy the happiness from preschool education work, but some teachers decrease and lose their working happiness. So we shall be concerned about the condition of Subject Well-being of preschool teachers and increase their feeling of well-being. It is not only the demand of preschool education career development, even also the inexorable expect of personal development of preschool teachers.

\section{B. Definition of Core Conception}

- Subjective Well-being (shorted as SWB) is a important comprehensive psychological index to value the living quality of human being. The basic structure of SWB mainly includes living satisfaction degree, positive emotion experience and negative emotion experience. It has three characters. First, subjectivity. It means to evaluate by appraiser's standard not by others standard. Second, stability. It is the relative stable value to measure long-term not the short-term emotion reaction and life satisfaction. Third, entirety. It is a comprehensive evaluation, includes emotion reaction evaluation and cognition judgment.

- In this paper, Preschool Teacher means the persons who are engaged in experience work of preschool education in Infant School. They include teachers, child-care workers and director of infant school.

\section{RESEARCH METHOD}

\section{A. Research Object}

We randomly sampled 108 in-service preschool teachers from 21 Infant Schools to finish the questionnaires. We recovered 102 validity questionnaires. And recovery percentage is $95 \%$.

TABLE I. Basic Constitution Condition of Surveyed Persons.

\begin{tabular}{|r|r|r|r|}
\hline & \multicolumn{1}{|c|}{ Items } & $\begin{array}{l}\text { Quanti } \\
\text { ty }\end{array}$ & Percentage \\
\hline \multirow{4}{*}{ Age } & Under 25 & 28 & $27 \%$ \\
\cline { 2 - 4 } & $26-35$ & 47 & $46 \%$ \\
\cline { 2 - 4 } & $36-45$ & 21 & $21 \%$ \\
\cline { 2 - 4 } & Above 46 & 6 & $6 \%$ \\
\hline \multirow{3}{*}{$\begin{array}{r}\text { Working } \\
\text { Age }\end{array}$} & Below 5 years & 36 & $35 \%$ \\
\cline { 2 - 4 } & $5-10$ years & 34 & $33 \%$ \\
\cline { 2 - 4 } & $11-20$ years & 24 & $24 \%$ \\
\hline \multirow{3}{*}{ Education } & Above 21 years & 8 & $8 \%$ \\
\cline { 2 - 4 } & $\begin{array}{r}\text { Graduated from } \\
\text { Secondary Specialized } \\
\text { School \& below }\end{array}$ & 27 & $26 \%$ \\
\cline { 2 - 4 } & $\begin{array}{r}\text { Graduated from } \\
\text { Junior College }\end{array}$ & 58 & $57 \%$ \\
\cline { 2 - 4 } & $\begin{array}{r}\text { Undergraduate and } \\
\text { above }\end{array}$ & 17 & $17 \%$ \\
\hline Income & Below 1000 RMB & 29 & $28 \%$ \\
\cline { 2 - 4 } & $1001-2000$ RMB & 57 & $56 \%$ \\
\hline
\end{tabular}




\begin{tabular}{|l|r|r|r|}
\hline & Above 2001 RMB & 16 & $16 \%$ \\
\hline
\end{tabular}

\section{B. Method}

We mainly used Psychological Measurement to measure these 102 surveyed persons and then deeply interviewed 15 preschool teachers.

\section{Tool}

We selected the abridged edition of Subjective Wellbeing Scale for Chinese Citizen (WSBS-CC) used for this research. This Scale consists of 20 items, i.e. Contentment Abundant Experience, Mental Health Experience, Social Confidence Experience, Growth and Progress Experience, Object Value Experience, Self-acceptance Experience, Body Health Experience, Balance of Mental State Experience, Interpersonal Adaptation Experience and Family Atmosphere Experience. Through many measurements, it is showed that this scale had good reliability and validity[3].

\section{RESULT AND DISCUSSION}

\section{A. Overall Situation}

We interviewed 30 preschool teachers and asked them that "In a word, do you feel happy with your recent situation?" The self-evaluation result of SWB showed in Table II.

TABLE II. Teachers' Self-evaluation Result of SWB

\begin{tabular}{|r|r|r|}
\hline & Quantity & Percentage \\
\hline Very Happy & 6 & $20 \%$ \\
\hline Happy & 11 & $37 \%$ \\
\hline Unhappy & 12 & $40 \%$ \\
\hline Very unhappy & 1 & $3 \%$ \\
\hline
\end{tabular}

On the whole, the result of Table II showed that the overall situation of SWB for Xi'an preschool teachers was not optimistic. There are only 57\% teachers satisfied with their situation. Nearly half of the teachers do not satisfy with their situation and even 3\% teachers felt very unhappy. The main reasons of low SWB for preschool teachers are mechanical and tedious work, misunderstanding from parents, no sense of safety and stability from work, and etc.

\section{B. 3.2 Scores of Each Dimension of SWB}

Table 3 shows the scores of each dimension of SWB from 102 preschool teachers in Xi'an through Subjective Wellbeing Scale for Chinese Citizen (WSBS-CC).

TABLE III. Scores of Each Dimension of SWB

\begin{tabular}{|r|r|r|}
\hline Dimension & Mean & $\begin{array}{r}\text { Std. } \\
\text { Deviation }\end{array}$ \\
\hline Contentment Abundant Experience & 4.9532 & 2.0852 \\
\hline Mental Health Experience & 6.0235 & 2.3203 \\
\hline Social Confidence Experience & 6.1415 & 1.8307 \\
\hline Growth and Progress Experience & 7.2637 & 1.9438 \\
\hline
\end{tabular}

\begin{tabular}{|r|r|r|}
\hline Object Value Experience & 6.3701 & 2.2903 \\
\hline Self-acceptance Experience & 6.9802 & 1.5820 \\
Body Health Experience & 5.8230 & 2.1087 \\
\hline Balance of Mental State Experience & 6.2142 & 2.1892 \\
Interpersonal Adaptation Experience & 6.4982 & 2.1276 \\
Family Atmosphere Experience & 6.7083 & 1.5823 \\
\hline
\end{tabular}

The scores of each dimension shows that SWB of Xi'an preschool teachers is not significant different from the average of the whole country. Only the scores of Social Confidence Experience, Interpersonal Adaptation Experience and Family Atmosphere Experience is a little bit lower than the average. But the difference has no statistical significance.

\section{SWB Scores of Different Variables}

TABLE IV. SWB Scores of Different Variables

\begin{tabular}{|r|r|r|}
\hline & Items & Score \\
\hline \multirow{4}{*}{ Age } & Under 25 & $67.92 \pm 11.35$ \\
\cline { 2 - 3 } & $26-35$ & $63.53 \pm 13.72$ \\
\cline { 2 - 3 } & $36-45$ & $61.95 \pm 12.13$ \\
\cline { 2 - 3 } & Above 46 & $55.44 \pm 12.75$ \\
\hline \multirow{3}{*}{$\begin{array}{c}\text { Working } \\
\text { Age }\end{array}$} & Below 5 years & $66.67 \pm 11.91$ \\
\cline { 2 - 3 } & 5-10 years & $63.94 \pm 12.11$ \\
\cline { 2 - 3 } & 11-20 years & $60.20 \pm 12.15$ \\
\hline & Above 21 years & $56.93 \pm 13.37$ \\
\hline \multirow{3}{*}{ Education } & $\begin{array}{r}\text { Graduated from Secondary } \\
\text { Specialized School and below }\end{array}$ & $54.38 \pm 12.25$ \\
\cline { 2 - 3 } & Graduated from Junior & $59.62 \pm 12.51$ \\
\cline { 2 - 3 } & College & \\
\cline { 2 - 3 } & Undergraduate and above & $61.92 \pm 11.95$ \\
\hline \multirow{3}{*}{ Income } & Below 1000 RMB & $61.62 \pm 13.09$ \\
\cline { 2 - 3 } & 1001-2000 RMB & $61.99 \pm 12.15$ \\
\cline { 2 - 3 } & Above 2001 RMB & $62.74 \pm 12.28$ \\
\hline
\end{tabular}

I) SWB of Preschool Teachers with Different Age: The analysis of Table IV showed that SWB of these teachers with four stages different age got lower and lower with the increasing of age. For the feeling of well-being, under $25>26-35>36-45>$ above 46 . For the young preschool teachers, they just get into community with enthusiasm to life and freshness to working, active thinking and rich emotion and also most of them are in love or in the beginning of marriage. So they are easy to show their much more positive emotion and get more happiness. However, the elder teachers are already the senior statesmen in the infant school. They will feel incompetent while dancing or playing with children in the infant school. They have their own finalized working style which will not promote and have heavier financial burden with old and yond at home. So they will easy to get more negative emotion.

II) SWB of Preschool Teachers with Different Working Age: The analysis of Table IV showed that SWB of these teachers with four stages of different working age got lower and lower with the increasing of working age. For the feeling of well-being, under 5 years $>5-10$ years 
$>11-20$ years $>$ above 21 years. The working age is related with the age. So the reason is same as that of the different age.

III) SWB of Preschool Teachers with Different Education Degree: The analysis of Table IV showed that the SWB of preschool teachers with different education degree are significant different. Preschool teachers with bachelor degree have the highest SWB. The increasing of SWB of preschool teachers is in direct proportion to the increasing of education degree. Teachers with higher education degree have proficiency working skill and higher study ability, and also can be easily to adapt the environmental changes. So teachers with higher education degree can get more confidence and honor in mind which will produce more positive emotion and well-being.

IV) SWB of Preschool Teachers with Different Income Level: There are so many researches to show the relationship between income and well-being. Different researches have different conclusion. The research of Bradburn showed that person with higher income will has higher positive emotion and while person with lower income will has more negative emotion (Bradburn, 19\%). The research of Cmapben showed that SWB of high-income person is higher than that of low-income person (Cmapben, 1976). However, there are also a lot of research show that income is unconcerned with SWB (He Ying, 2000). Duan Jianhua considered that SWB will decrease along with the increasing of income when income increased to a certain level (Duan Jianhua, 1996).

The analysis of Table IV showed that the SWB of preschool teachers with different income are not significant different. The limit digressive rule may affect the economic factor to influence well-being. When the income of someone achieve a certain level, more money would not bring more happiness. The increasing of income will lead persons to focus on money problems which will be transferred into under-controlled social element (i.e. self-development).

V) Factors Influencing the SWB of Preschool Teacher: Through the collation of interview records, it is realized that the SWB of preschool teachers mainly come from sincere love and care from children, simple and guileless of children, trust, respect and approval from children's parents, the support and approval from leaders, achieved development and unremitting pursue of education career during working, correct realization and aesthetic attitude to work, and also the achievability from teaching.

The main reasons for loss of career well-being of preschool teachers include low social position, disrespect and misunderstanding from children's parents, deification of expect to preschool teachers from society, loss of the space and time to communicate with adult world and outside world when stay in children's world, Specific characteristics, short golden period and early recession of career life cycle, conflict between organization management and teaching autonomy, the feelings of nervous, tired and even breakdown of teachers caused by the specific characteristics of preschool education, Individualistic logic uphold when realization of teaching works, pain caused by the forgotten by children, and also the sadness caused by the leaving of children.

\section{CONCLUSION}

A. The overall situation of SWB for Xi'an preschool teachers is not optimistic.

Only $57 \%$ of teachers satisfied with their situation. But nearly half of the teachers do not satisfy with their situation and even 3\% teachers felt very unhappy.

B. SWB of these teachers with four stages different age got lower and lower with the increasing of age.

For the feeling of well-being, under $25>26-35>$ 36-45 $>$ above 46 .

C. SWB of these teachers with four stages of different working age got lower and lower with the increasing of working age.

For the feeling of well-being, under 5 years $>5-10$ years $>11-20$ years $>$ above 21 years.

\section{SWB of preschool teachers with different income are not significant different.}

E. The main factors which can affect SWB of preschool teachers are, children, parents, infant school, career identification degree, social recognition, and etc.

\section{SUGGESTION}

The external value and internal value of education stress its social service function and individual developing function respectively. "The teaching career has giant challenge of personality and intelligence. So it not only has the life value to help students to improve their individual development, but also has the internal life value to promote selfsurpassing for teachers themselves."[4] So, it is respectful for teachers' life value to focus on well-being of preschool teachers and increase their well-being index.

First, to build a good social environment and increase the social position of preschool teachers. It is very important to form reasonable social expectation and cultivate social environment of honor teachers and esteem truth. While stressing the offer and responsibility of teachers, it is should better to give a rational positioning to professional role of teachers. Teachers will experience their own value during working and have higher well-being only to increase publicity to lead society to focus on preschool teachers and understand their working nature and also to promote the social position of preschool teachers.

Second, to promote the professional developing level of preschool teachers. The professional developing level is di- 
rectly related with present manner of teaching activities, condition of emotion communication between teachers and children and well-being experience produced by teaching. The preschool teachers with unskilled business and low professional developing level are struggling to finish their work. So they are easy to produce low achievability, high frustration, less positive emotion, more negative emotion, less happiness and more Job burnout. With the Sufficient teaching professional development, teachers will have more powerful ability to build well-being education to get sufficient teaching achievement and to produce stronger career well-being. So it is required for teachers to strengthen education idea, professional knowledge and teaching skill through all kinds of forms and to rapidly finish professional leap from new teachers to skilled teachers. [5]

Third, to create a good mental environment to teachers for infant school.

Management level of infant school will build a perfect management rules on the one hand and let teachers feel human kindness during management and promote teachers' belongingness and identification to infant school on the other hand. Management level of infant school shall optimize management mechanism and achieve equal pay for equal work, evaluation of equal distribution and system of rewards and penalties.

Forth, to cultivate the personal optimistic quality of preschool teachers. It is noticed to cultivate teachers to have optimistic living faith, open and bright living attitude, scientifically and healthy living method and elegance life interests. Only in this way, preschool teachers will enjoy their lives, work happily and gain more well-being experience from mundane and trivial normal teaching activities.

\section{REFERENCES}

[1] Cai Jun, "Approach to happiness, the end-result of the professional development of preschool teachers, " Education Guide , vol.4,pp.9,2011.

[2] Diener E. Subjective well-being, Psychological Bulletin, vol.95, pp.542-575,1984.

[3] Xing Zhanjun, Measurement Well-being: Measurement and Research of Subjective Well-being, People Publishing House, pp.116,2005.

[4] Ye Lan, Pedagogic Principle, People's Education Press, pp.285,2007.

[5] Cai Jun, Approach to happiness: the end-result of the professional development of preschool teachers. Education Guide, vol.4, pp.9. 2011. 